\title{
FoxP3- and CD8-positive Infiltrating Immune Cells Together Determine Clinical Outcome in Colorectal Cancer
}

\author{
Eliane C. M. Zeestraten • Anneke Q. Van Hoesel • \\ Frank M. Speetjens • Anand G. Menon • Hein Putter • \\ Cornelis J. H. van de Velde $\cdot$ Peter J. K. Kuppen
}

Received: 26 April 2011 / Accepted: 22 June 2011 / Published online: 6 July 2011

(C) The Author(s) 2011. This article is published with open access at Springerlink.com

\begin{abstract}
Immune cells are known to affect clinical outcome in colorectal cancer. Subsets of immune cells can both support and inhibit immunological interaction with tumor cells. We examined the clinical impact of $\mathrm{T}$ cells that are supposed to be responsible for the down regulation of a $\mathrm{T}$ cell response: regulatory $\mathrm{T}$ cells or Tregs. The study population $(n=76)$ consisted of a random population of colorectal cancer patients who did not receive any (neo-) adjuvant therapy, with a median follow-up time of 7.3 years (range 0.1-23.1 years). Expression of FoxP3 was used as an immunohistochemical marker to identify Tregs. We considered FoxP3+ cells present in tumor stroma and tumor epithelium separately, and related results to clinical outcome and to data on CD8+ immune cell infiltration that we previously obtained in the same patient cohort. All samples showed presence of Foxp3+ cells and in the majority of the patients $(85.5 \%)$ these cells were also present in the tumor epithelial compartment. A relative high level of Foxp3+ cells in the tumor epithelium was significantly related to down regulation of HLA Class I expression ( $p$-value 0.03). There was a trend, but no significant relation, towards a longer overall survival ( $p$-value; 0.084$)$ and disease-free survival ( $p$-value; 0.073 ) when high levels of Foxp3+ cells were present in the tumor epithelium. More importantly, the ratio of CD8+/Foxp3+
\end{abstract}

E. C. M. Zeestraten - A. Q. Van Hoesel - F. M. Speetjens A. G. Menon - C. J. H. van de Velde • P. J. K. Kuppen $(\triangle)$ Department of Surgery, Leiden University Medical Center, Albinusdreef 2, Leiden 2333 ZA, The Netherlands

e-mail: p.j.k.kuppen@lumc.nl

\section{H. Putter}

Department of Medical Statistics, Leiden University Medical Center, Leiden, the Netherlands cells did show a significant correlation with distantrecurrence-free survival. This was the case for both Foxp3+ cells specifically located in the tumor epithelium ( $p$-value 0.024 ) as well as in the stroma compartment ( $p$-value 0.018). Unfortunately due to the small sample size the ratios did not retain their statistical significance in multivariate analysis. These results provide further evidence that local interactions in the cancer microenvironment between tumor cells and immune cells are not only determined by tumor cell-related factors like HLA expression, but also by interactions among immune cells.

Keywords FoxP3 - CD8 - Tumor-immune infiltration . Colorectal cancer. Cancer prognosis

\section{Introduction}

The process of tumor development in colorectal cancer (CRC) is one of the most studied and best characterized models of tumorigenesis in the world today. At least six features can be identified that hallmark tumor growth and development $[1,2]$. Three of which are related to the immune system. Tumor cells may acquire the ability to thrive in a inflamed micro-environment, to evade immune recognition and, to suppress immune reactivity [3]. The adaptive immune system and its key players, especially cytotoxic T Lymphocytes (CTL), play an important role in controlling tumor growth and metastasis. Naito et al. were the first to demonstrate that infiltrating CTL are a prognostic factor in CRC [4]. Due to their genetic instability, tumor cells may arise with a phenotype that makes them less sensitive to immune surveillance, thus escaping CTL recognition. This phenotype includes down regulation or complete loss of one or more HLA class I 
alleles. This enables tumor cells to minimize their presentation of tumor-associated antigens (TAA) and, therefore, diminish their chance of recognition and subsequently destruction by CTL [5-8]. Another mechanism to evade immunosurveillance is to suppress immune reactivity by attraction of immunosuppressive regulatory $\mathrm{T}$ cells (Tregs) into the tumor micro-environment. Both, down regulation of HLA class I, and presence of Tregs, have been shown to be of clinical relevance in various types of solid tumors [912]. CRC-related studies that describe HLA class I expression in relation to clinical prognosis have, however, rendered contrasting results. Some studies were not able to determine any significant relation between HLA class I expression and survival, while others did [13-16]. When a significant relation could be established, a total lack of HLA class I expression always resulted in more favorable prognosis. This is probably due to the fact that HLA Class I negative metastatic cells in the circulation will be targets for destruction by Natural Killer (NK) cells that are abundantly present in the circulation but not in solid tumors [17, 18]. Partial expression, however, was related to either a better or worse prognosis compared to high expression $[15,16]$. Similar, there are a variety of studies describing the presence of Tregs in tumor tissue in relation to clinical outcome. In case of ovarian cancer, three studies were able to establish that high Treg infiltration was associated with a poor prognosis $[10,19,20]$. In colorectal cancer, however, 4 studies describing the presence of Tregs in cancer tissues have rendered contrasting results. Loddenkemper et al. performed an analysis on 40 colorectal tumor samples and could not establish a significant relation between the presence of Foxp3+ Tregs or the ratio CD $8+/$ Tregs with outcome [21]. In contrary, a recently published study by Suzuki et al., a predictive value of the intra-tumoral ratio of CD8+ T cells and Foxp3+ Tregs could be established [22]. A third study by Salama et al. using a Tissue Micro Array of 967 stage II and III CRC patients was able to significantly correlate the presence of Tregs to clinical outcome parameters [23]. High Foxp3+ Treg density in the normal mucosa of patients was associated with a worse prognosis, while a high density in the tumor tissue was associated with improved survival. Finally, a study of Deng et al. was able to significantly correlate the accumulation of Foxp3+ Tregs in draining lymph nodes to disease [24]. The latter four publications as well as the studies on the significance of HLA Class I expression in colorectal cancer all have in common that they were performed on mixed study populations containing both adjuvant and nonadjuvant treated, metastatic and non-metastatic patients and patients of which tumor microsatellite status was often not determined. Besides, the presence of Foxp3+ Tregs was expressed in several ways; either as their presence in the tumor epithelium, in the tumor stroma or as a ratio with
CD8+ cells. All these variations in study methods make it difficult to recapitulate the results of these studies into one overall conclusion. Therefore, the importance of HLA class I expression and Foxp3+ Treg infiltration in relation to the presence of CD8 + CTLs still remains to be determined in CRC patients. The purpose of this study was to analyze the presence of Foxp3+ Tregs and relate the data to the data on infiltrating immune cells and HLA expression that we have previously obtained in a random cohort of patients, without adjuvant treatment [7]. The data on Foxp3+ Tregs were also correlated with clinico-pathologic variables such as TNM (Tumor Node Metastasis) classification, tumor differentiation grade and the tumors microsatellite stability status (MSS/MSI), as well as with outcome parameters such as overall survival (OS) and disease free survival (DFS).

\section{Patients and Methods}

\section{Patients}

Between January 1980 and December 1992, 266 consecutive patients underwent curative resection with postoperative follow up for a colorectal adenocarcinoma at the Leiden University Medical Center. Within this cohort, previously described by Tollenaar et al. and Menon et al., 76 patients were identified who did not receive any (neo-) adjuvant therapy and of whom data was available on CD8+ lymphocyte infiltration, tumor microsatellite stability status and HLA Class I expression [7, 15, 25]. CD8+ infiltration was scored as the number of CD8+ leukocytes per tumor area (leukocytes $/ \mathrm{mm} 2$ tumor epithelium). The average leukocyte infiltration of 25 fields per tumor section was calculated and defined as the intraepithelial leukocyte infiltration. In addition, leukocytes in the tumor stroma and at the tumor margin were assessed semi quantitatively into 'none-poor' or 'moderate-marked' leukocyte infiltration. The tumor microsatellite status was determined with MLH1-based immunohistochemistry. MLH1 expression was categorized as absent if the majority of the tumor cells lacked nuclear MLH1 expression; this suggests a microsatellite instable (MSI) tumor phenotype. If nuclear MLH1 expression was present in the majority of the tumor cells samples were indicated to be microsatellite stable (MSS).

HLA Class I expression was determined previously by immunohistochemistry using the monoclonal antibodies HCA2 and HC10 according to the defined standard method of the International HLA and Immunogenetics Workshop (IHIW) in which HCA2 and HC10 staining are scored in 5 categories. (0-5\% positivity, $5-25 \%$ positivity, $25-50 \%$ positivity, $50-75 \%$ positivity and $75-100 \%$ positivity). In 
66 out of the $76(87 \%)$ tumors, both HCA2 and HC10 staining could be quantified and, therefore, were available for evaluation of total HLA Class I expression. Three groups were identified according to a standardized method and defined as (1) HLA class I loss (staining of both HCA2 and $\mathrm{HC} 10$ ) was less than $5 \%$ of the tumor cells; (2) HLA class I reduced expression (staining of either HCA2 or HC10 was less than $50 \%$ of the tumor cells); and (3) HLA class I expression (staining of both HCA2 and $\mathrm{HC} 10$ was more than $50 \%$ of the tumor cells) [8].

Tumors were staged according to the TNM criteria [26]. Known tumor characteristics included differentiation grade, Jass lymphocyte infiltration score, DNA microsatellite status, and presence of mucinous characteristics. Median follow- up was 7.3 years (range 0.1-23.1 years). Patient and tumor- characteristics are shown in Table 1.

Immunohistochemistry

A Foxp3/laminin immunohistochemical double staining of tumor sections was performed to evaluate the presence of Foxp3+ regulatory T cells in both the epithelial and stromal compartment of the primary tumors. FFPE (formalin-fixed paraffin-embedded) tissue sections of $5 \mu \mathrm{m}$ thickness were prepared on aminopropylethoxysilane (APES)-coated slides and dried at $37^{\circ} \mathrm{C}$. Tissue sections were deparaffinized in xylene, submerged in $0.3 \%$ hydrogen-peroxidase methanol to block endogenous peroxidase, and rehydrated in a graded ethanol series. For antigen-retrieval, tissues were soaked in $0.01 \mathrm{M}$ citrate buffer $(\mathrm{pH} 6)$ at $100^{\circ} \mathrm{C}$ for $10 \mathrm{~min}$. After rinsing in PBS, tissues were incubated overnight with antiFOXP3 (1:300, ABCAM AB20034). On the second day, Biotin-labeled Rabbit-anti-Mouse secondary antibody (30 min, 1:200, DAKO) followed by Streptavidin-Biotincomplex (30 min, 1:100, DAKO) was used for signal amplification. After $5 \mathrm{~min}$ of soaking in a $0.05 \mathrm{M}$ Tris- $\mathrm{HCl}$ solution, tissues were developed for $10 \mathrm{~min}$ with 3,3-diamino-benzidine tetrahydrochloride (DAB) for visualization. Next, tissues were transferred to a $0.01 \%$ trypsin solution and soaked at $37^{\circ} \mathrm{C}$ for $10 \mathrm{~min}$. Rabbit polyclonal anti-laminin (1:50, Sigma L9393) was applied to the sections for overnight incubation. Subsequently, tissues were incubated with Biotin-labeled Swine-anti-Rabbit (1:400, DAKO) for $30 \mathrm{~min}$, followed by StreptavidinBiotin-complex (1:100, DAKO) for $30 \mathrm{~min}$. A blue signal was achieved by developing the tissue sections for $12 \mathrm{~min}$ in a 4-chloro-1-naphtol solution. Methyl green was used for nuclear counterstaining. Finally, all tissue sections were dehydrated and mounted in Kaiser's glycerol. FFPE sections of tonsil and normal colon tissues were included as positive controls for the Foxp3 and laminin staining and as negative controls by replacing incubations with either the primary antibody or secondary antibody by mock incubations.
Table 1 Clinico-pathological characteristics of the 76 patients median follow-up 7.3 years (range $0.1-23.1$ years)

\begin{tabular}{|c|c|c|}
\hline Characteristic & $\mathrm{N}$ & $(\%)$ \\
\hline \multicolumn{3}{|l|}{ Sex } \\
\hline male & 44 & 57.9 \\
\hline female & 32 & 42.1 \\
\hline \multicolumn{3}{|l|}{ Age (yrs) } \\
\hline median & 69.8 & \\
\hline range & $31-85$ & \\
\hline \multicolumn{3}{|l|}{ Tumor location } \\
\hline colon left-sided & 29 & 38.2 \\
\hline colon right-sided & 29 & 38.2 \\
\hline rectum & 19 & 23.7 \\
\hline \multicolumn{3}{|l|}{ TNM Stage } \\
\hline I & 31 & 40.8 \\
\hline II & 12 & 15.8 \\
\hline III & 33 & 43.4 \\
\hline \multicolumn{3}{|l|}{ Differentiation grade } \\
\hline poor & 42 & 56.8 \\
\hline moderate & 18 & 24.3 \\
\hline well & 14 & 18.9 \\
\hline unknown & 2 & - \\
\hline \multicolumn{3}{|c|}{ Mucinous Characteristics } \\
\hline yes & 19 & 27.5 \\
\hline no & 50 & 72.5 \\
\hline unknown & 7 & - \\
\hline \multicolumn{3}{|c|}{ Jass Lymphocyte Infiltration } \\
\hline absent/scarce & 23 & 33.3 \\
\hline moderate/marked & 46 & 66.7 \\
\hline unknown & 7 & - \\
\hline \multicolumn{3}{|l|}{ Microsatellite stability } \\
\hline MSS & 63 & 82.9 \\
\hline MSI & 13 & 17.1 \\
\hline \multicolumn{3}{|l|}{ HLA status } \\
\hline High expression & 43 & 65.2 \\
\hline Reduced expression & 18 & 27.3 \\
\hline Loss of expression & 5 & 7.6 \\
\hline unknown & 10 & - \\
\hline
\end{tabular}

Table 1 shows the clinico-pathological characteristics of all of the 79 primary colorectal cancer patients included in this study

Yrs years, TNM Tissue Node Metastasis, MSS Micro Satellite Stable, MSI Micro Satellite Instable, HLA Human Leukocyte Antigen

Evaluation of the Immunohistochemistry

The number of Foxp3+ cells in primary colorectal tumor tissues was microscopically evaluated by two independent observers (ECMZ and AQvH). Microscopic evaluation was done without previous knowledge of patient characteristics or disease outcome. The laminin-staining served as demarcation to distinguish the epithelial from stromal tumor 
compartments and other tissue. For counting, an ocular grid was used at 100x magnification. First the total amount of Foxp3+ cells (tot-Foxp3+) was counted in 5 randomly chosen, separate grid fields (surface-area of $3 \mathrm{~mm}^{2}$ ) in each tumor. This approach enabled to determine the number of positive cells per $\mathrm{mm}^{2}$ tumor tissue. The tot-Foxp $3+$ count was further subdivided according to location of the Foxp3+ cells: Foxp3+ cells located actually in the tumor epithelium, which means there was direct contact with the tumor cells and the Foxp3+ cells, were counted as tumor-Foxp3+ cells (t-Foxp3+), and Foxp3+ cells located in the tumor stroma as stromal-Foxp3+ cells (s-Foxp3+). Inter-observer conformity was calculated using the intraclass correlation test. Intraclass correlation coefficients for single measures were $0.93,0.82$ and $0.93(\mathrm{p}<0.001)$ for the tot-Foxp3+, the t-Foxp3+ and the $\mathrm{s}-\mathrm{Foxp} 3+$ cell counts respectively. Observer counts were averaged and used to calculate the final t-Foxp3 + and sFoxp3+ counts and the t-Foxp3+/tot-Foxp3+ ratio for each tumor sample. Previously determined number of CD8+ cells present in the tumor epithelium (t-CD8+) were used to calculate the $\mathrm{t}-\mathrm{CD} 8+/ \mathrm{t}-$ or s-Foxp3+ [7].

\section{Statistical Analysis}

Statistical analyses were performed with SPSS software version 16.0 (SPSS Inc, Chicago, IL). To test whether the mean levels of Foxp3+ cells differed between the tumor and the stroma compartments the Wilcoxon Signed ranks test was applied. The Chi-squared test was used to evaluate associations between the presence of t-Foxp3+ cells, s-Foxp3+ cells and the t-Foxp3+/ tot-Foxp3+ ratio and various clinico-pathologic parameters, and HLA Class I expression and the presence of CD8+ cells. For the survival analysis, date of surgery was used as the entry date for analysis. The Kaplan-Meier method was used for overall survival (OS), disease-free survival (DFS), distantrecurrence-free survival (DRFS) and local-recurrence-free Survival (LRFS) and the log-rank test for comparison of the survival curves. OS, DFS, DRFS and LRFS were defined as follows; date of any event of interest minus entry date. Hazard ratios were calculated the Cox proportional hazards analysis for uni- and multivariable analysis. Only parameters that were of statistical significance in the univariate analysis were analyzed in the multivariate model. Significance of hazard ratios was tested with the Wald's test. All statistical tests were two-tailed with a 0.05 significance level.

\section{Results}

Immunohistochemistry

The laminin IHC double staining demarcated the tumor epithelium from the stromal compartment within the tumors. (Fig. 1) Therefore, the exact location and number of the Foxp3+ cells within the tumor tissue could be determined. For all 76 cases, Foxp3 infiltration data were obtained. Foxp $3+$ cells were found to be present in the stromal compartment of all tumors. In the majority of the patients (85.5\%) Foxp3+ cells were also present in the tumor epithelium. The mean number of Foxp3+ cells in the tumor epithelium (t-Foxp3+) was $0,25 / \mathrm{mm} 2$ with a range of $0-1.73$, and in the tumor stroma (s-Foxp3+) $5.84 / \mathrm{mm} 2$, ranging from $0,43-20,87$. This was a significant difference ( $p$-value $<0.000$ ). Because the counts of both locations of FoxP3 + cells were skewed to the right of the range, the median was used for further analysis as a cut-off point for the presence of Foxp $3+$ cells. The median was $0.133 / \mathrm{mm} 2$ for t-Foxp3 and 4.818/mm2 for s-Foxp3 respectively.

The numbers of $\mathrm{CD} 8+$ cells were previously determined in the same patient cohort. As described in the study by Menon et al., the cut-off used for the number of CD8+ cells in the tumor epithelium (t-CD8+), was at the 75 percentile $\left(65\right.$ cells $/ \mathrm{mm}^{2}$ ) [7]. The presence of $\mathrm{CD} 8+$ cells at the tumor margin $(\mathrm{m}-\mathrm{CD} 8+)$ or tumor stroma $(\mathrm{s}-\mathrm{CD} 8+)$ was scored qualitatively as either no or poor infiltration, moderate, and marked infiltration. The scores in the entire study population did not statistically significantly differ from those of the patients used in this subset analysis.

Association of Presence and Location of Foxp3+ Cells with Clinico-pathological Parameters, HLA Class I Expression, and Presence of CD8+ Cells

Neither the presence of t-Foxp3+ or s-Foxp3+ showed a significant correlation to any of the standard clinicopathological parameters (Table 2). Their presence was also

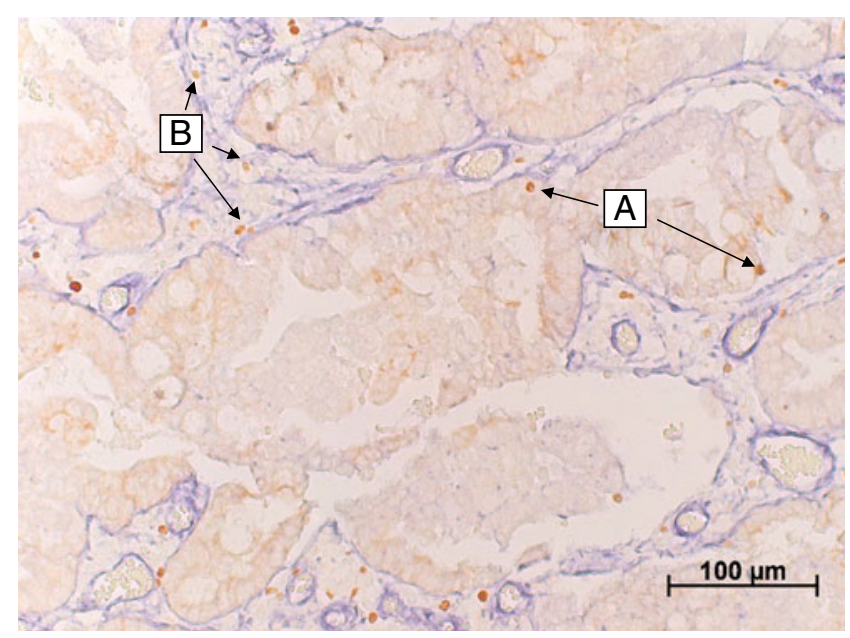

Fig. 1 A representative image of the Foxp3 and laminin double staining. In which the laminin (blue) clearly demarcates the tumor stroma from the tumor epithelium (light brown area). In this image typical examples of epithelial Foxp3+ cells (a) and Foxp3+ cells in the tumor stroma can be identified (b) 
Table 2 Presence of Foxp3+ Tregs in tumor compartments in relation to clinico-pathological characteristics and HLA status

\begin{tabular}{|c|c|c|c|c|c|c|}
\hline Characteristic & $\begin{array}{l}\% \text { s-Foxp } 3+ \\
>\text { median }\end{array}$ & $p$-value & $\begin{array}{l}\% \text { t-Foxp } 3+ \\
>\text { median }\end{array}$ & $p$-value & $\begin{array}{l}\text { \%t-Foxp3+/tot- Foxp3+ } \\
>\text { median }\end{array}$ & $p$-value \\
\hline \multicolumn{7}{|l|}{$\operatorname{Sex}(n=76)$} \\
\hline Male & 52,3 & 0.642 & 47,7 & 0.941 & 52,3 & 0.642 \\
\hline Female & 46,9 & & 46,9 & & 46,9 & \\
\hline \multicolumn{7}{|l|}{ Age $(n=76)$} \\
\hline$<65$ years & 47,4 & 0.913 & 52,6 & 0.910 & 47,4 & 0.913 \\
\hline $65-70$ years & 44,4 & & 44,4 & & 44,4 & \\
\hline $70-75$ years & 52,6 & & 42,1 & & 52,6 & \\
\hline$>75$ years & 55 & & 50 & & 55 & \\
\hline \multicolumn{7}{|c|}{ Tumor location $(\mathrm{n}=76)$} \\
\hline Left colon & 41,4 & 0.498 & 37,9 & 0.150 & 41,4 & 0.410 \\
\hline Right colon & 55,2 & & 44,8 & & 51,7 & \\
\hline Rectum & 55,6 & & 66,7 & & 61,1 & \\
\hline \multicolumn{7}{|l|}{ TNM Stage $(\mathrm{n}=76)$} \\
\hline I & 54,8 & 0.501 & 51,6 & 0.439 & 45,2 & 0.437 \\
\hline II & 58,3 & & 58,3 & & 66,7 & \\
\hline III & 42,4 & & 39,4 & & 48,5 & \\
\hline \multicolumn{7}{|c|}{ Differentiation $(n=74)$} \\
\hline Poor & 46,3 & 0.505 & 53,7 & 0.426 & 58,5 & 0.243 \\
\hline Moderate & 61,1 & & 38,9 & & 38,9 & \\
\hline Well & 42,9 & & 35,7 & & 35,7 & \\
\hline \multicolumn{7}{|l|}{ Mucinous $(n=69)$} \\
\hline Yes & 57,9 & 0.377 & 52,6 & 0.622 & 57,9 & 0.377 \\
\hline No & 46 & & 46 & & 46 & \\
\hline \multicolumn{7}{|c|}{ Jass Classification $(n=69)$} \\
\hline Absent-scarce & 47,8 & 0.865 & 47.8 & 1.0 & 56,5 & 0.395 \\
\hline Moderate-marked & 50 & & 47.8 & & 45,7 & \\
\hline \multicolumn{7}{|l|}{ MSI status $(n=76)$} \\
\hline MSS & 46 & 0.128 & 46 & 0.607 & 49,2 & 0.761 \\
\hline MSI & 69,2 & & 53,8 & & 53,8 & \\
\hline \multicolumn{7}{|l|}{ HLA status $(n=66)$} \\
\hline Reduced/loss & 43,5 & 0.678 & 52,2 & 0.423 & 65,2 & 0.03 \\
\hline Expression & 48,8 & & 41,9 & & 37,2 & \\
\hline
\end{tabular}

Table two shows the relation of either the presence of Foxp $3+$ cells in the tumor stroma (s-Foxp $3+)$, in the tumor epithelia, $(\mathrm{t}-\mathrm{Foxp} 3+)$ and the ratio t-Foxp3+/total amount of Foxp3 + (t-Foxp3+/tot-Foxp3+) present to clinico-pathological parameters and HLA expression. Presence is expressed as the percentage of patients that showed levels of s-Foxp3+ and t-Foxp3+ or a ratio above the cut-off level set in all cases at the median TNM Tissue Node Metastasis, MSS Micro Satellite Stable, MSI Micro Satellite Instable, HLA Human Leukocyte Antigen

not related to HLA class I expression status of the tumor. The ratio of t-Foxp3+/tot-Foxp3+ did show a statistically significant relationship with HLA class I expression. When HLA class I expression was low, no expression or reduced expression within the tumor, the ratio of t-Foxp3/tot-Foxp3 was higher at a $p$-value of 0.03 (Table 2). Patients with reduced HLA class I expression were therefore more likely to have relatively higher numbers of Foxp $3+$ cells in the tumor epithelium compared to the number of s-Foxp3.

In concordance with the data previously shown by Menon et al., the number of t-CD8+ cells significantly correlated with tumor stage and was inversely correlated with HLA status [7].

The presence of t-Foxp3+ cells or the ratio of t-Foxp3+/ tot-Foxp3+ cells did not show any statistical significant relationship with the presence of $\mathrm{CD} 8+$ cells at any location in the tumor. In contrast, the presence of s-Foxp $3+$ cells did show a significant relation to the presence of CD8+ cells at the tumor margin. When more CD8+ cells were present in the tumor margin the number of Foxp3+cells in the stroma also increased statistically significantly ( $p$-value: 0.043 , Table 3). 
Table 3 Presence of CD8+ CTLS in the various tumor compartments related to the presence of Foxp3 positive cells

\begin{tabular}{|c|c|c|c|c|c|c|}
\hline & $\begin{array}{l}\% \text { s-Foxp } 3+ \\
>\text { median }\end{array}$ & $p$-value & $\begin{array}{l}\% \text { t-Foxp3+ } \\
>\text { median }\end{array}$ & $p$-value & $\begin{array}{l}\text { \%t-Foxp3+/tot-Foxp3+ } \\
>\text { median }\end{array}$ & $p$-value \\
\hline \multicolumn{7}{|c|}{$\mathrm{t}-\mathrm{CD} 8+(\mathrm{n}=67)$} \\
\hline Low & $46 \%$ & 0.183 & $46 \%$ & 0.621 & $50 \%$ & 0.834 \\
\hline High & $64.7 \%$ & & $52 \%$ & & $47.1 \%$ & \\
\hline \multicolumn{7}{|c|}{$\mathrm{s}-\mathrm{CD} 8+(\mathrm{n}=67)$} \\
\hline no-poor & $41 \%$ & 0.162 & $46.2 \%$ & 0.698 & $51 \%$ & 0.400 \\
\hline moderate & $66.7 \%$ & & $55.6 \%$ & & $55.6 \%$ & \\
\hline marked & $60 \%$ & & $40 \%$ & & $30 \%$ & \\
\hline \multicolumn{7}{|c|}{$\mathrm{m}-\mathrm{CD} 8+(\mathrm{n}=64)$} \\
\hline no-poor & $35.3 \%$ & 0.043 & $52 \%$ & 0.422 & $52.9 \%$ & 0.697 \\
\hline moderate & $46.7 \%$ & & $40 \%$ & & $53.3 \%$ & \\
\hline marked & $76.5 \%$ & & $40.8 \%$ & & $41.2 \%$ & \\
\hline
\end{tabular}

Table three shows the relation of the presence of Foxp3 + cells in the tumor stroma (s-Foxp3+), in the tumor epithelium, $(\mathrm{t}-\mathrm{Foxp} 3+)$ and the ratio t-Foxp3+/total amount of Foxp3+ cells (t-Foxp3+/tot-Foxp3+) present to the presence of CD8+ cells in either the tumor epithelium (t-CD8+), the tumor stroma $(\mathrm{s}-\mathrm{CD} 8+)$ or the tumor margin $(\mathrm{m}-\mathrm{CD} 8+)$. The determination and qualification of the presence of CD8+ cells has been previously described [7]

Association of the t-CD8+/Foxp3+ Ratio

with Clinico-pathological Parameters and HLA

Class I Expression

To determine whether the number of Foxp3+ cells combined with the number of CD8+ cells was related to clinico-pathological parameters or HLA Class I expression, their ratio was calculated. This was performed for both $\mathrm{t}-$ Foxp3+ and s-Foxp3+ cell counts. Absolute data on CD8+ cells was only available for the t-CD8+ counts. The ratio tCD8+/t-Fox3+ or t-CD8+/s-Foxp3+ could be determined for 63 cases. The median t-CD8+/t-Foxp3+ ratio was 73, median t-CD8+/s-Foxp3+ ratio was 4.03. Due to the distribution of the data the median was used as a cut-off point. Neither of these ratios was related to clinicopathological parameters or HLA class I expression (data not shown).

Association of Foxp3+ Cells and the CD8+/Foxp3+ with Clinical Prognosis

The presence of t-Foxp3+ cells or s-Fop $3+$ cells was not related to tumor recurrence ( $p$-values of 0.598 and 0.446 respectively). Patients with high t-Foxp $3+$ cell counts compared to patients with low t-Foxp3+ counts showed a trend towards both a longer Overall Survival (OS) time (122 months vs. 96,7 months, $\mathrm{p}=0.084)$ and a longer Disease Free Survival (DFS) time (109 months vs. 83 months, $p=0.073$ ). (Figs. 2, and 3). Previously, Menon et al. have shown that $\mathrm{t}-\mathrm{CD} 8+$ cells was an independent prognostic factor of a longer disease-free survival [7]. Also the ratio of the number of t-CD8+ cells and number of $t$ Foxp $3+$ cells $(\mathrm{t}-\mathrm{CD} 8+/ \mathrm{t}-\mathrm{Foxp} 3+$ ) showed a trend towards a longer OS time. A ratio above the median, indicating a relative larger number of t-CD8+ cells compared to t-Foxp3+ cells, was related to a longer OS time of 130 months compared to 87 months at a ratio below the median ( $p$-value; 0.053 ). The same trend was seen for DFS, however this was again not significant at a $p$-value of 0.081 (Figs. 2, and 3). The t-CD8/ s-Foxp3 + ratio was never related to OS or DFS. Interestingly, both the $\mathrm{t}-\mathrm{CD} 8+/ \mathrm{t}-\mathrm{Foxp} 3+$ and $\mathrm{t}-\mathrm{CD} 8+/ \mathrm{s}-\mathrm{Foxp} 3+$ ratio were significantly related to Distant Recurrence Free Survival (DRFS). Both ratios showed a longer DRFS time for patients when above median: 214 months vs. 142 months for the tCD8+/s-Foxp3+ ratio at a $p$ - value of 0.018 , and 226 vs. 158 months for the t-CD8+/t-Foxp3+ ratio at a $p$-value of 0.024 (Fig. 4).

\section{Univariate and Multivariate Analysis}

Uni - and multivariate analysis was performed to calculate hazard ratios, to identify whether the t-CD8+/t-Foxp3+ and t-CD8+/s-Foxp3 ratios were independent of prognostic significance for DRFS. Analysis included known risk factors such as age, TNM stage, tumor microsatellite status, etc. For the DRFS, advanced TNM stage as well as the tCD8+/t-Foxp3+ and s-Foxp+ ratios were statistically significant predictors in the univariate analysis. The hazard ratios for TNM stage II and III were 4,294 (CI95\% 0,717$25,713)$ and $8,125(\mathrm{CI} 95 \% 1,847-36,533)$ respectively at a $\mathrm{p}$-value of 0.003 . The hazard ratios of t-CD $8+/ \mathrm{t}$-Foxp3+-and s-Foxp3+ cells were 0.190 (p-value 0.034) and 0.294 (p-value 0.034 ). However neither of these parameters was able to retain their value as an independent significant predictor of DRFS in multivariate analysis (data not shown). Also for OS analysis, univariate and multivariate analysis were executed with the 
Fig. 2 Kaplan Meier graphs for Foxp3 levels in the tumor epithelium (t-Foxp3+) (a) and as a ratio with $\mathrm{CD} 8+$ in the tumor epithelium (t-CD8+/t-Foxp3+) (b) in relation to Overall Survival

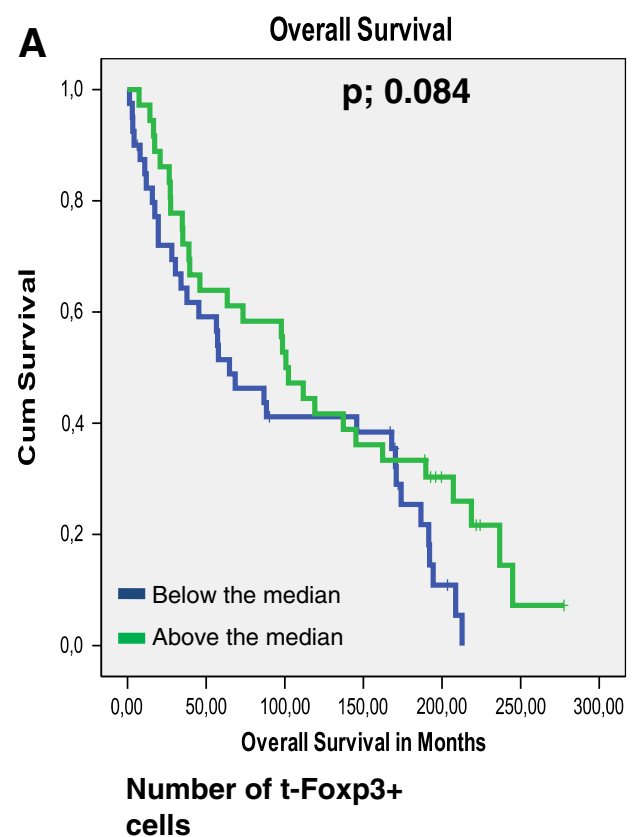

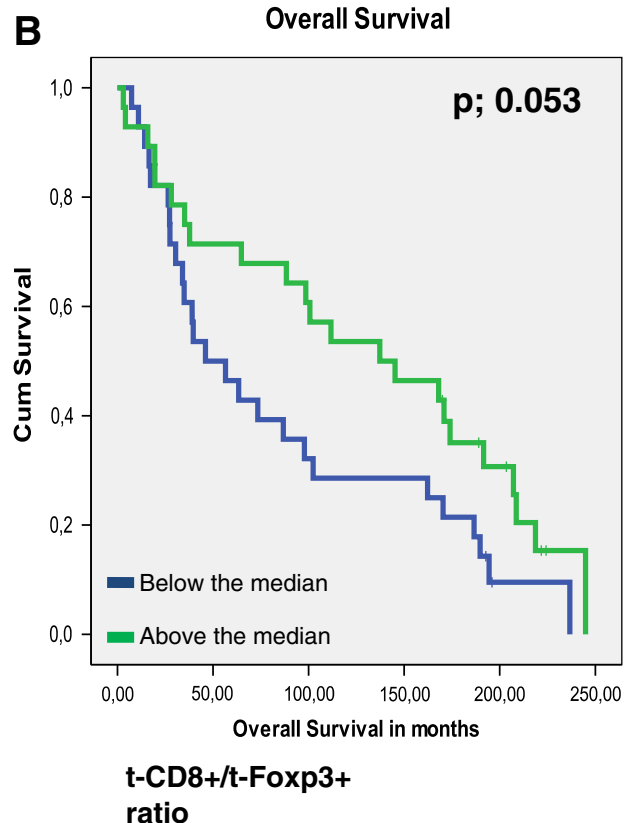

same parameters. In univariate analysis only mucinous differentiation showed a statistically significant relation to OS. (HR 0.504; CI95\% 0.288-0.882; $p$-value 0.016) This effect did not remain in the multivariate analysis (data not shown)

\section{Discussion}

The ability of tumor cells to thrive in a chronically inflamed microenvironment is only one of three important immune system-related hallmarks of tumor growth and develop- ment. Two other features also play a major role in the process of tumorigenesis. First, tumors are able to develop certain features that make it possible for them to evade immune recognition [27]. Among others, these features comprise down regulating or even complete loss of HLA class I expression. This way, for the most part they lose the capability to become recognized and attacked by the immune system. Tumor cells may also be poorly immunogenic because of insufficient presence of TAA presentation or co-activating signals. Secondly, tumor cells may evade immune reactivity by restraining an anti-tumor immune
Fig. 3 Kaplan Meier graphs for the t-CD8/t-Foxp3 levels (a) and the t- CD8/s-Foxp3+ (b) relation to Distant recurrence Free Survival
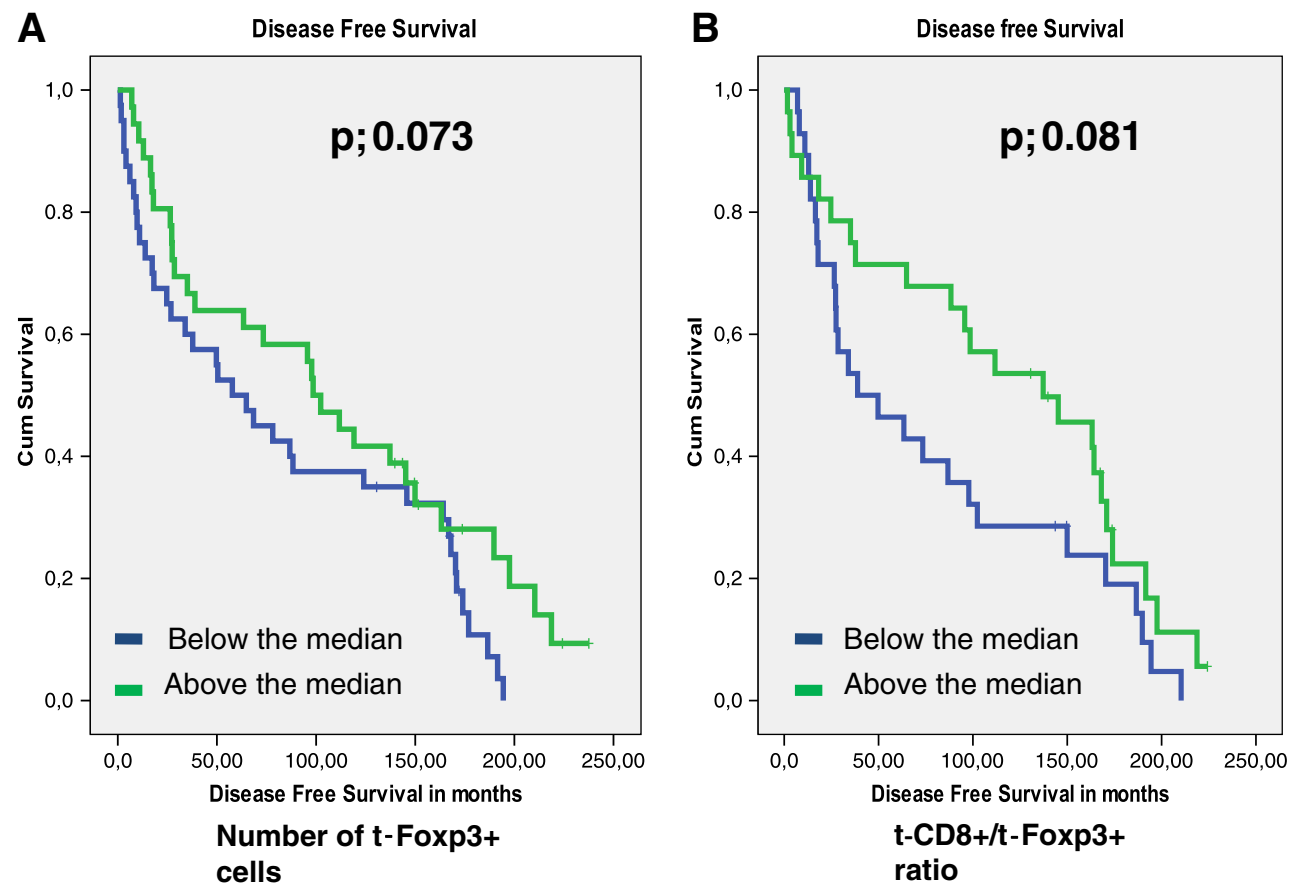
Fig. 4 Kaplan Meier graphs for Foxp3 levels in the tumor epithelium (t-Foxp3+) (a) as a ratio with $\mathrm{CD} 8+$ in the tumor epithelium (t-CD8+/t-Foxp3+) (b) in relation to Disease Free Survival
A

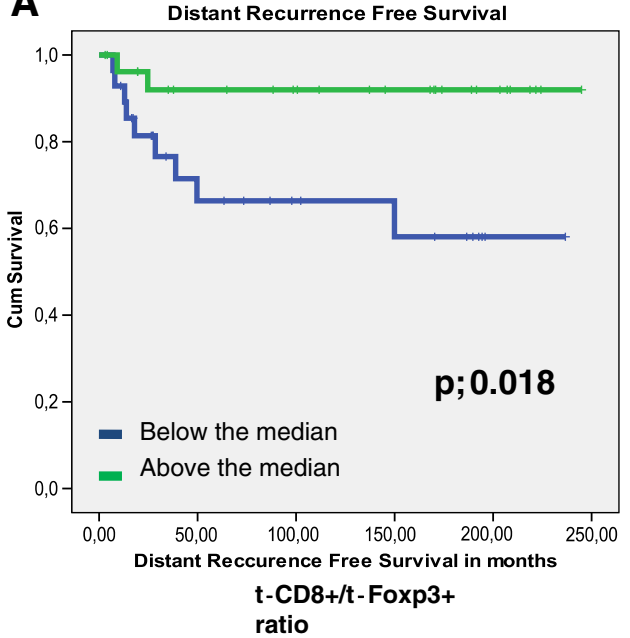

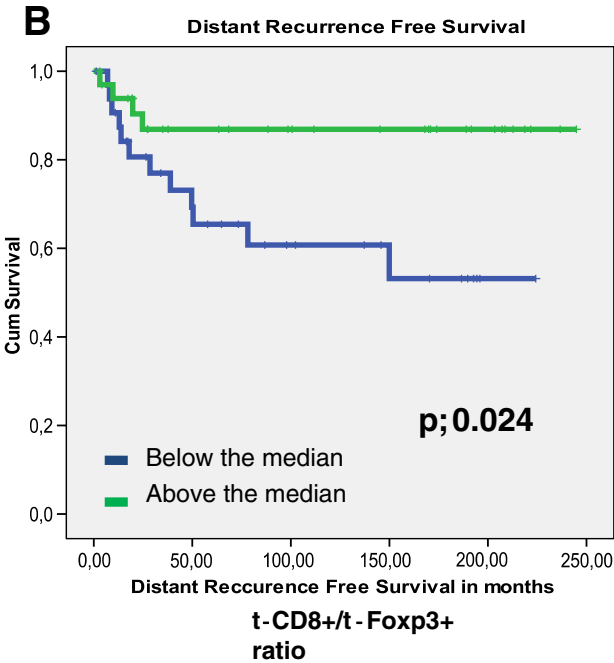

response [5-8]. The latter currently gets a lot of attention in tumor immunology as it has become clear that tumor cells may attract immunosuppressive cells such as Foxp3+ regulatory $\mathrm{T}$ cells (Tregs). Tregs inhibit the development of autoimmune responses, but also are capable of impeding antitumor immune responses $[28,29]$. In this study we were able to identify and quantify both these features in colorectal tumor samples. In addition we found that both features were seemingly interconnected. The mechanism by which Foxp3+ Tregs become attracted to the tumor microenvironment remains yet to be discovered. Two hypotheses can be postulated. Either tumor cells actively attract these cells or the overall inflammatory character induced by tumor growth also induces the influx of Tregs into the tumor microenvironment. Our results showed that down regulation of HLA class I was associated with a relative higher level of epithelial Foxp3+ cells as compared to the number of Foxp3+ cells in the tumor stromal compartment. This seems to be contradicting, but may be a reflection of an earlier anti-tumor immune reaction. Possibly, tumor reactive CTL caused selective outgrow of HLA loss tumor variances. The immune cells involved, such as the Tregs and CD8+ cells, apparently remain present as illustrated by our results.

Our data also illustrate the importance of the interplay between various types of immune cells in the tumor microenvironment in determining clinical outcome as neither the presence of Foxp3+ cells nor CD8+ cells was statistically significantly prognostic. Combined, however, the ratio of these cells significantly predicted clinical outcome with respect to distant recurrence of disease, suggesting a functional mutual relationship. Previous data published on the effect of Foxp3+ cells in CRC patients is rather inconclusive with respect to their prognostic relevance [21-24]. One of the reasons for lack of consistency in the results may be variation in study population size as the larger studies by Salama et al. and
Suzuki et al. both showed a relationship between Foxp3 + cell presence in tumors and clinical prognosis, while studies on smaller populations did not $[22,23]$. The data presented here, even though derived from a relative small patient cohort, indicates that a more comprehensive approach is probably of greater importance than large patient numbers. This approach, combining data on two types of immune cells that are expected to interact, but also tumor characteristics that may interfere, will better show the involvement and clinical relevance of the immune system in colorectal cancer. A comparable approach was chosen by Loddenkemper et al. and Suzuki et al., but in our study this approach was extended by the incorporation of more data regarding key elements of the process of tumor development [21, 22]. Tumor microsatellite status, and other tumor characteristics that were previously shown to be of clinical importance, including HLA class I status, were included in our analysis. The major advantage of this comprehensive 'mapping' approach at the level of immune regulation in colorectal cancer is the clinical applicability of the data, as the information might be used to determine treatment allocation, like suggested before. For example, a study by De Kruijf et al. showed that the presence of Foxp3+ cells alone in breast cancer patients had no prognostic value [9]. However, when combined with level of HLA expression the data showed a prognostic effect in adjuvant treated patients. It was postulated that counteraction of Tregs by chemotherapy allowed CTL to affect tumor metastases development, but only when HLA expression was intact [9]. Further research conducted in stage III and IV adjuvantly treated patients will determine whether such an effect is also present in CRC patients.

In conclusion, we were able to determine a prognostic effect on disease recurrence free survival of the presence of Foxp3+ cells, in either the tumor stromal compartment or the tumor epithelium, but only when combined with data on CD8+ cells. This indicates the importance of a comprehensive approach 
that shows the interplay between members of the immune system in CRC patients. We hypothesize that studying even more cell types and molecules involved, such as NK ligands, co-stimulating molecules, and activating or suppressing cytokines, will lead to a better understanding of the tumor-immune system interaction. This will eventually help us to better predict patient prognosis and will direct adjuvant treatment.

Open Access This article is distributed under the terms of the Creative Commons Attribution Noncommercial License which permits any noncommercial use, distribution, and reproduction in any medium, provided the original author(s) and source are credited.

\section{References}

1. Hanahan D, Weinberg RA (2011) Hallmarks of cancer: the next generation. Cell 144(5):646-674

2. Hanahan D, Weinberg RA (2000) The hallmarks of cancer. Cell 100(1):57-70

3. Ohtani H (2007) Focus on TILs: prognostic significance of tumor infiltrating lymphocytes in human colorectal cancer. Cancer Immun 7:4

4. Naito Y, Saito K, Shiiba K, Ohuchi A, Saigenji K, Nagura H, Ohtani H (1998) CD8+ T cells infiltrated within cancer cell nests as a prognostic factor in human colorectal cancer. Cancer Res 58 (16):3491-3494

5. Halvorsen TB, Seim E (1989) Association between invasiveness, inflammatory reaction, desmoplasia and survival in colorectal cancer. J Clin Pathol 42(2):162-166

6. Murphy J, O’Sullivan GC, Lee G, Madden M, Shanahan F, Collins JK, Talbot IC (2000) The inflammatory response within Dukes' B colorectal cancers: implications for progression of micrometastases and patient survival. Am J Gastroenterol 95(12):3607-3614

7. Menon AG, Janssen-van Rhijn CM, Morreau H, Putter H, Tollenaar RA, van de Velde CJ, Fleuren GJ, Kuppen PJ (2004) Immune system and prognosis in colorectal cancer: a detailed immunohistochemical analysis. Lab Invest 84(4):493-501

8. Speetjens FM, de Bruin EC, Morreau H, Zeestraten EC, Putter H, van Krieken JH, van Buren MM, van VM, Dekker-Ensink NG, van de Velde CJ, Kuppen PJ (2008) Clinical Impact of HLA Class I Expression in Rectal Cancer. Cancer Immunol Immunother 57(5):601-9

9. de Kruijf EM, van Nes JG, Sajet A, Tummers QR, Putter H, Osanto S, Speetjens FM, Smit VT, Liefers GJ, van de Velde CJ, Kuppen PJ (2010) The predictive value of HLA class I tumor cell expression and presence of intratumoral tregs for chemotherapy in patients with early breast cancer. Clin Cancer Res 16(4):1272-1280

10. Curiel TJ, Coukos G, Zou L, Alvarez X, Cheng P, Mottram P, Evdemon-Hogan M, Conejo-Garcia JR, Zhang L, Burow M, Zhu Y, Wei S, Kryczek I, Daniel B, Gordon A, Myers L, Lackner A, Disis ML, Knutson KL, Chen L, Zou W (2004) Specific recruitment of regulatory $\mathrm{T}$ cells in ovarian carcinoma fosters immune privilege and predicts reduced survival. Nat Med 10 (9):942-949

11. Hiraoka N, Onozato K, Kosuge T, Hirohashi S (2006) Prevalence of FOXP3 + regulatory $\mathrm{T}$ cells increases during the progression of pancreatic ductal adenocarcinoma and its premalignant lesions. Clin Cancer Res 12(18):5423-5434

12. Gao Q, Qiu SJ, Fan J, Zhou J, Wang XY, Xiao YS, Xu Y, Li YW, Tang ZY (2007) Intratumoral balance of regulatory and cytotoxic $\mathrm{T}$ cells is associated with prognosis of hepatocellular carcinoma after resection. J Clin Oncol 25(18):2586-2593
13. Benevolo M, Mottolese M, Piperno G, Sperduti I, Cione A, Sibilio L, Martayan A, Donnorso RP, Cosimelli M, Giacomini P (2007) HLA-A, -B, -C expression in colon carcinoma mimics that of the normal colonic mucosa and is prognostically relevant. Am J Surg Pathol 31(1):76-84

14. Moller P, Momburg F, Koretz K, Moldenhauer G, Herfarth C, Otto HF, Hammerling GJ, Schlag P (1991) Influence of major histocompatibility complex class I and II antigens on survival in colorectal carcinoma. Cancer Res 51(2):729-736

15. Menon AG, Morreau H, Tollenaar RA, Alphenaar E, Van PM, Putter H, Janssen-van Rhijn CM, van de Velde CJ, Fleuren GJ, Kuppen PJ (2002) Down-regulation of HLA-A expression correlates with a better prognosis in colorectal cancer patients. Lab Invest 82(12):1725-1733

16. Watson NF, Ramage JM, Madjd Z, Spendlove I, Ellis IO, Scholefield JH, Durrant LG (2006) Immunosurveillance is active in colorectal cancer as downregulation but not complete loss of MHC class I expression correlates with a poor prognosis. Int J Cancer 118(1):6-10

17. Sandel MH, Speetjens FM, Menon AG, Albertsson PA, Basse PH, Hokland M, Nagelkerke JF, Tollenaar RA, van de Velde CJ, Kuppen PJ (2005) Natural killer cells infiltrating colorectal cancer and MHC class I expression. Mol Immunol 42(4):541-546

18. Hokland M, Kuppen PJ (2005) Natural killer cells: from "Disturbing" background to central players of immune responses. Mol Immunol 42(4):381-383

19. Sato E, Olson SH, Ahn J, Bundy B, Nishikawa H, Qian F, Jungbluth AA, Frosina D, Gnjatic S, Ambrosone C, Kepner J, Odunsi T, Ritter G, Lele S, Chen YT, Ohtani H, Old LJ, Odunsi K (2005) Intraepithelial CD8+ tumor-infiltrating lymphocytes and a high $\mathrm{CD} 8+/$ Regulatory $\mathrm{T}$ cell ratio are associated with favorable prognosis in ovarian cancer. Proc Natl Acad Sci USA 102(51):18538-18543

20. Wolf D, Wolf AM, Rumpold H, Fiegl H, Zeimet AG, MullerHolzner E, Deibl M, Gastl G, Gunsilius E, Marth C (2005) The expression of the regulatory $\mathrm{T}$ cell-specific forkhead box transcription factor FoxP3 is associated with poor prognosis in ovarian cancer. Clin Cancer Res 11(23):8326-8331

21. Loddenkemper C, Schernus M, Noutsias M, Stein H, Thiel E, Nagorsen D (2006) In situ analysis of FOXP3+ regulatory T cells in human colorectal cancer. J Transl Med 4:52

22. Suzuki H, Chikazawa N, Tasaka T, Wada J, Yamasaki A, Kitaura Y, Sozaki M, Tanaka M, Onishi H, Morisaki T, Katano M (2010) Intratumoral CD8(+) T/FOXP3 (+) cell ratio is a predictive marker for survival in patients with colorectal cancer. Cancer Immunol Immunother 59(5):653-661

23. Salama P, Phillips M, Grieu F, Morris M, Zeps N, Joseph D, Platell C, Iacopetta B (2009) Tumor-Infiltrating FOXP3+ T regulatory cells show strong prognostic significance in colorectal cancer. $\mathrm{J}$ Clin Oncol 27(2):186-192

24. Deng L, Zhang H, Luan Y, Zhang J, Xing Q, Dong S, Wu X, Liu M, Wang S (2010) Accumulation of Foxp3+ T regulatory cells in draining lymph nodes correlates with disease progression and immune suppression in colorectal cancer patients. Clin Cancer Res 16(16):4105-4112

25. Tollenaar RA, van Krieken JH, van Slooten HJ, Bruinvels DJ, Nelemans KM, van den Broek LJ, Hermans J, van Dierendonck $\mathrm{JH}$ (1998) Immunohistochemical detection of P53 and Bcl-2 in colorectal carcinoma: no evidence for prognostic significance. $\mathrm{Br}$ J Cancer 77(11):1842-1847

26. Greene FL, Sobin LH (2008) The staging of cancer: a retrospective and prospective appraisal. CA Cancer J Clin 58(3):180-190

27. Cavallo F, De GC, Nanni P, Forni G, Lollini PL. 2011: the Immune Hallmarks of Cancer. Cancer Immunol Immunother 2011; 60(3): 319-26

28. von Herrath MG, Harrison LC (2003) Antigen-Induced regulatory T cells in autoimmunity. Nat Rev Immunol 3(3):223-232

29. Zou W (2006) Regulatory $T$ cells, tumour immunity and immunotherapy. Nat Rev Immunol 6(4):295-307 